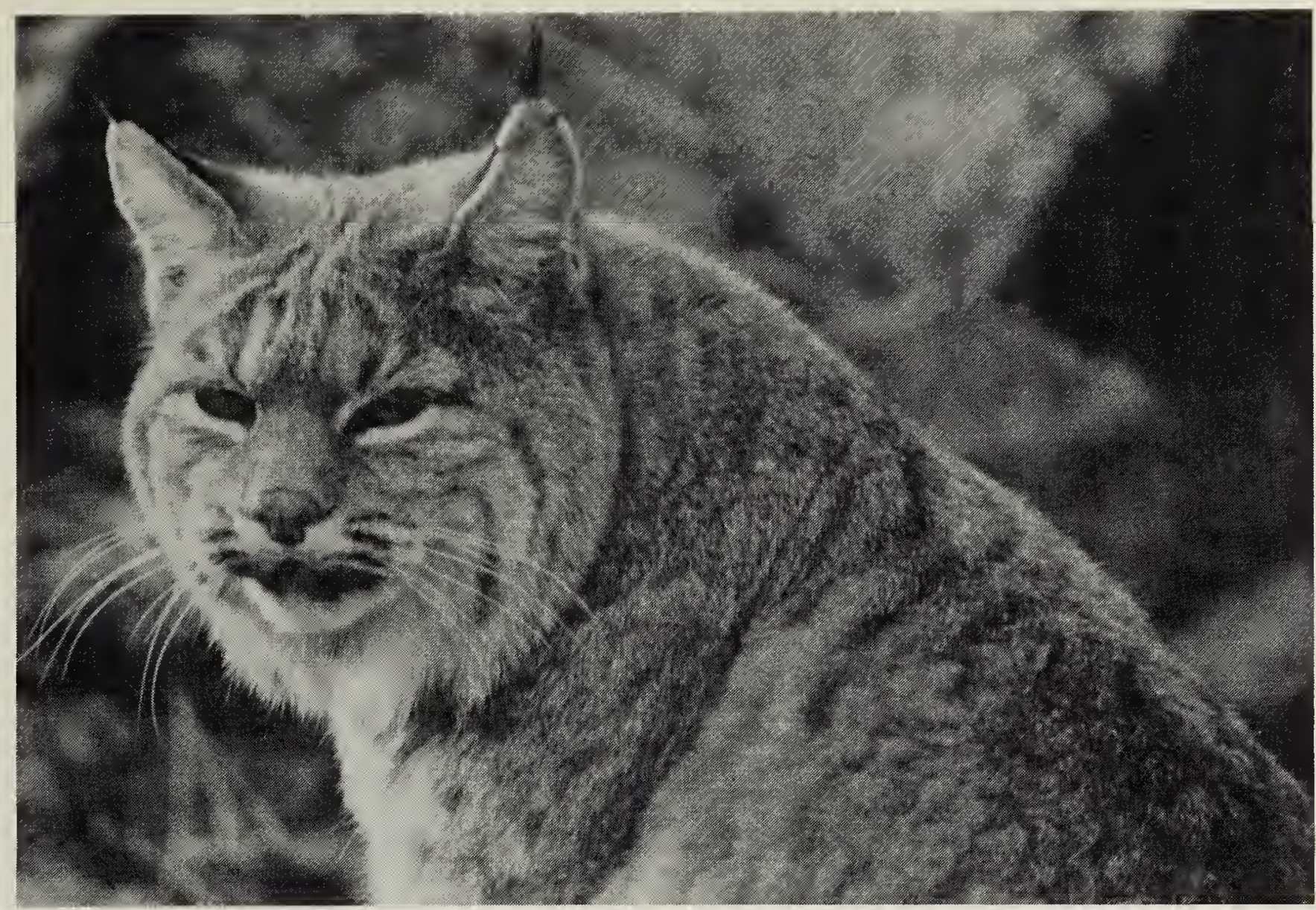

During this same period, while lying on the same lawn chair, I was attracted by soft "kruk" calls coming at a slow, regular beat from the grass some distance away. Upon investigating I discovered a large Wood Frog grasped crosswise in the jaws of a medium-sized Plains Garter Snake. As frogs are not all that common here, I sided with the snake, which had managed to find and obtain such a fine one. I watched for the approximately half hour it took the snake to work its way up the front of and then engulf the hapless frog, a morbid but fascinating sight that must be seen to be believed.

This was the first year I was unable to find any Northern Leopard Frogs at Crooked Lake. During the 1950s they were abundant, and as recently as 1992 I was still able to find a few along the waterline after dark. This year only a dozen or so Wood Frogs were seen, which I do not recall finding in the past except for the odd individual.

The smallest of the little predators that I observed was one of the common orb-weaving spiders that have webs under each light or lighted cabin window. While brushing my teeth outside the back door of the cabin one evening I noted a Smalleyed Sphinx (Paonias myops), a medium-sized but nevertheless powerful sphinx moth, blunder into a web which I assumed would not hold him for more than a few seconds. The spider dashed out and mounted the moth, bringing to mind the story of the mouse on a date with the giraffe. Hope springs eternal thought I. To my surprise and admiration, within moments the spider had the upper hand, and the moth went limp. In the morning all that remained was the carcass with wings attached.

- Gary G. Anweiler, 7212 - 103rd Avenue, Edmonton, AB. T6A OV1

\section{BARNYARD BOBCAT}

A hot sunny mid-morning in June 1994 found me working in the barn on our ranch in the South Saskatchewan River Valley. Suddenly the 
sound of Long-billed Curlews giving their warning calls was heard. Soon several Black-billed Magpies joined the curlews in a noisy chorus. Must be a coyote around, I thought, as magpies often follow the coyotes. My horse had been standing outside the corral waiting to be let in. Suddenly he gave a loud snort and galloped away to the far corner of his pasture. He's not afraid of coyotes, so I hurried outside to see what was causing a disturbance. Standing partly hidden behind a slab fence, I looked across the horse pasture and saw the back of a tawny animal about the size of a large collie dog coming through the tall waving grass. It came up to the corral and stuck its head through the rails. It was a Bobcat, only 16 feet away from me across the small west corral. I moved slightly, the Bobcat noticed me, then he trotted up to the feedstacks through the centre of the yard between house and barn and disappeared into a grove of maple trees.

As Bobcats are extremely shy animals, I was surprised to see one come around occupied buildings in the daytime, acting as unconcerned as a barn cat would be. My guide books describe the Bobcat as tawny with spots and streaks, shorter ear tufts than a Lynx. Tail black on upperside only and striped with black or brown, whereas the Lynx has a complete black tip on the tail and the tail is not striped.

- Daisy D. Meyers, Box 218, Leader, SK. SON $1 \mathrm{HO}$

\section{A HOODED WARBLER RECORD IN THE EASTERN QU'APPELLE VALLEY}

On 3 July 1995 I was making my last mist net check in a Monitoring Avian Productivity and Survivorship (MAPS) study area in the Qu'Appelle Valley north of Whitewood. I was closing all the nets and found a lone bird in the last net. At first glance 1 thought it was a male Wilson's Warbler because it had a black cap. I thought this was early in the summer for Wilson's Warbler to show up, but I had caught them before this. When I reached into the mist net to free the bird, I realized this was not a normal Wilson's Warbler. It felt too large and then I saw the white tail spots. I knew then that this was a species I had never before seen.

I carefully extracted the bird and placed it in the bird bag knowing that too often it is the rare birds that seem to escape prematurely before banding and recording. Once back at the banding area, I checked through my reference material, and it was clear I had caught a female Hooded Warbler. This female had an extensive black cap extending from its eye back to its neck. As well, it had a faint black necklace. The plumage and wing measurements fit the species' description.

Perhaps more interesting was the brood patch on this bird. The skin was vascularized with some fluid buildup. It is unlikely this bird was breeding in the study area as I had not seen any males or heard their song in the area. After I released the bird, it did not reappear on subsequent mist netting and other outings in the area.

I have often caught unusual birds at the height of breeding season species like Tennessee Warbler, Nashville Warbler and Yellowbreasted Chat - unusual because they are out of their normal breeding range. This species, however, is way out of its normal breeding range of eastern United States and the extreme south of Ontario. There are two other confirmed records of Hooded Warblers in Saskatchewan.

- John Pollock, Box 353, Whitewood, SK. SOG 5 CO 